\title{
Central Endogenous Opioid Inhibition of Supraoptic Oxytocin Neurons in Pregnant Rats
}

\author{
A. J. Douglas, ${ }^{1}$ I. Neumann, ${ }^{2, a}$ H. K. M. Meeren, ${ }^{3, b}$ G. Leng, ${ }^{4}$ L. E. Johnstone, ${ }^{1}$ G. Munro, ${ }^{1, c}$ and J. A. Russell ${ }^{1}$ \\ ${ }^{1}$ Department of Physiology, University Medical School, Teviot Place, Edinburgh, EH8 9AG, United Kingdom, \\ ${ }^{2}$ Department of Medical Physiology, University of Calgary, Alberta, Canada, ${ }^{3}$ Department of Physiology, University \\ of Leiden, 2300 RC Leiden, The Netherlands, and ${ }^{2}$ Department of Neurobiology, The Babraham Institute, \\ Babraham, Cambridge, CB2 4AT, United Kingdom
}

\begin{abstract}
Naloxone increases oxytocin secretion in pregnant rats, suggesting restraint by endogenous opioids but we have previously reported that oxytocin nerve terminals in the neural lobe become desensitized to opioid actions in late pregnancy. Therefore, we sought evidence for opioid inhibition on oxytocin cell bodies and their inputs at this time. In conscious 21 d pregnant rats naloxone increased the number of neurons expressing Fos (an indicator of neuronal activity) in the supraoptic nucleus (SON) but had no effect on $16 \mathrm{~d}$ pregnant or virgin rats. Release of oxytocin within the SON, measured by microdialysis in conscious rats, was also increased by naloxone in late pregnancy but not before. Nor-binaltorphimine, a specific $\kappa^{-}$opioid antagonist, did not increase Fos or affect oxytocin release within the SON in any group. In anesthetized rats the firing rate of SON neurons was recorded and oxytocin neurons identified by an excitatory response to intravenous cholecystokinin. Naloxone potentiated the cholecystokinin-induced firing rate response on day 21 of pregnancy but not in 16 d pregnant or virgin rats. Blood sampling in anesthetized rats showed that naloxone also increased the oxytocin secretory response to cholecystokinin in late pregnant rats.

We conclude that in late pregnancy, after day 16, endogenous opioids inhibit oxytocin neurons either directly, on their cell bodies, or presynaptically on inputs. These endogenous opioids do not act through $k$ - opioid receptors since nor-binaltorphimine was ineffective, but may act via $\mu$-opioid receptors. Thus, the opioids restrain premature oxytocin secretion until parturition when there is a high demand for it.
\end{abstract}

[Key words: endogenous opioids, pregnancy, Fos, elec-

Received Oct. 26, 1994; revised Feb. 13, 1995; accepted Feb. 16, 1995.

This work was supported by an Agriculture and Food Research Council Linked Research Group Grant and the IBRO/British Council. I.N. was supported by a Human Frontier Science Programme (Strasbourg). L.E.J. and G.M. were supported by AFRC Research Studentships. H.K.M.M. was an Erasmus exchange student from the Department of Physiology, University of Leiden, The Netherlands. We thank. Prof. R. Landgraf (Munich) for RIA of oxytocin in dialysates and Mrs. K. Grant and Mrs. G. Grant (Edinburgh) for their assistance with histology.

Correspondence should be addressed to Dr. A. J. Douglas. Department of Physiology, University Medical School, Teviot Place, Edinburgh, EH8 9AG. UK.

"Present address: Max Planck Institute of Psychiatry, Clinical Institute, Munich, Germany.

'Present address: Katholicke University, Nijmegen, The Netherlands.

Present address: Oregon Regional Primate Center, Beaverton, OR.

Copyright (C) 1995 Society for Neuroscience 0270-6474/95/155049-09\$05.00/0 trophysiology, oxytocin release into the soN/from dendrites, oxytocin secretion, microdialysis, cholecystokinin]

During pregnancy, in preparation for parturition, the oxytocin content of the rat neural lobe increases progressively (for example, Douglas et al., 1993b), and the accumulated excess is secreted during parturition itself to stimulate uterine contractility and fetal expulsion. The increase in neural lobe oxytocin is not conspicuously a result of increased synthesis since there is little change in hypothalamic oxytocin mRNA (Brooks, 1992; Douglas and Russell, 1994), but at least in part appears to be a consequence of an active restraint of secretion. We have shown that endogenous opioids inhibit oxytocin neurons in late pregnancy since injection of the opioid antagonist naloxone into conscious late pregnant rats rapidly increases oxytocin secretion (Hartman et al., 1986; Douglas et al., 1993b). Opioids may restrain oxytocin secretion either by $\mu$ - or $\kappa$-opioid mechanisms acting on the oxytocin cell body in the hypothalamus (Pumford et al., 1993 ) or by preterminal $\kappa$-mediated inhibition at the neural lobe (Zhao et al., 1988; Russell et al., 1993). Oxytocin neurons are highly susceptible to inhibition by either $\mu$-or $\kappa$-agonists, which thus suppress the milk-ejection reflex (Clarke and Wright, 1984), oxytocin secretion, and Fos expression in supraoptic magnocellular neurons in parturition (Russell et al., 1989; Douglas and Russell, 1993; Douglas et al., 1993a; Luckman et al., 1993).

In virgin rats inhibition of oxytocin secretion by endogenous opioids appears to be via receptors on oxytocin nerve terminals in the neural lobe, since naloxone increases plasma oxytocin concentration without increasing oxytocin neuron firing rate (Leng et al., 1992). In early- to mid-pregnancy secretion of endogenous opioids, such as extended enkephalins or dynorphins colocalized with oxytocin (Leng et al., 1994), in the neural lobe may locally inhibit oxytocin secretion and induce downregulation of K-opioid receptor binding sites (Sumner et al., 1992). However, by the end of pregnancy oxytocin nerve terminals in the neural lobe appear to be desensitized to opioid actions and naloxone is relatively ineffective at this time in potentiating oxytocin secretion from the isolated neural lobe (Douglas et al., 1993b). Thus, from this mismatch at the end of pregnancy between enhanced activity of systemically administered naloxone and declining efficiency of naloxone at the neural lobe level, we have speculated that at the end of pregnancy a second endogenous opioid mechanism acts more centrally on the oxytocin neurons in the hypothalamus.

We now report studies testing the hypothesis that there is a central component of endogenous opioid inhibition of oxytocin 
neurons in late pregnancy. We have performed parallel experiments to seek endogenous opioid restraint in pregnancy of the expression of Fos protein (a sign of neuronal activation) in the supraoptic nucleus (SON) and oxytocin release within the SON. In addition we have sought endogenous opioid restraint of inputs to oxytocin neurons in pregnancy by measuring the effects of naloxone on stimulus evoked oxytocin neuron firing rate and stimulated oxytocin secretion.

Some of the data have previuusly been reported in abstract form (Douglas et al., 1993, 1994a,b).

\section{Materials and Methods}

\section{Experiment 1. The effect of opioid antagonists on SON neuron} Fos expression in pregnancy

Female Sprague-Dawley, age-matched rats were given food and water ad libitum and housed according to standard conditions in Edinburgh (Douglas et al., 1993b). Rats were mated overnight with sexually experienced males and pregnancy was confirmed by the presence of a vaginal plug of semen which had been shed into the mating cage the following morning (day 0 of pregnancy). In the initial study we sought evidence for opioid inhibition on day 21 of pregnancy using naloxone. (1) Conscious $21 \mathrm{~d}$ pregnant rats were injected intraperitoneally (i.p.) with either vehicle $(0.9 \%$ saline, $0.5 \mathrm{ml} / \mathrm{kg}, n=6)$ or naloxone $(5 \mathrm{mg} / \mathrm{kg}, 10 \mathrm{mg} / \mathrm{ml}$, $n=6)$ and virgin rats $(n=6)$ were injected with naloxone, all between 10.30 and $11.45 \mathrm{hr}$. Two virgin females were injected with $1.5 \mathrm{M} \mathrm{NaCl}$ ( $4 \mathrm{ml} / \mathrm{kg}$, i.p.) as positive controls for Fos expression (Giovannelli et al., 1992; Hamamura et al., 1992). (2) Subsequently we partly repeated the experiment, and also tested naloxone in animals on day 16 of pregnancy and included virgin and $21 \mathrm{~d}$ pregnant groups to test for specific $\kappa$-opioid effects. Conscious virgin rats were injected intraperitoneally with either vehicle $(0.9 \%$ saline, $0.5 \mathrm{ml} / \mathrm{kg}, n=6)$, or the $\kappa$-receptor antagonist, nor-binaltorphimine dihydrochloride (17,17'-bis(cyclopropylmethyl)$6,6^{\prime}, 7,7^{\prime}$-tetradehydro- $4,5,4^{\prime}, 5^{\prime}$-diepoxy-6,6'-(imino) $\left[7,7^{\prime}\right.$-bimorphinan]-3,3',14,14'-tetrol dihydro-chloride, norBNI, Research Biochemicals International, supplied by Semat, St. Albans, U.K., $1 \mathrm{mg} / \mathrm{kg}, n=6), 16$ d pregnant rats with either vehicle $(n=6)$ or naloxone $(n=6)$ and 21 $\mathrm{d}$ pregnant rats with either vehicle $(n=3)$ or naloxone $(n=3)$ or nor BNI $(n=6)$ between 11.20 and $13.30 \mathrm{hr}$. Animals which had obviously started labor or had given birth to one or more pups were not included in either experiment; any with less than four pups in utero post mortem were also excluded. Ninety minutes after injection all rats were decapitated, and their brains were rapidly removed, frozen in crushed dry ice, and stored at $-70^{\circ} \mathrm{C}$ until cryostat sectioned transversely at $15 \mu \mathrm{m}$ and slide mounted. Sections of brain containing SON were then fixed ( $4 \%$ paraformaldehyde in phosphate buffer, $\mathrm{pH} 7.2-7.4$ for $20 \mathrm{~min}$ ) and endogenous peroxidases were deactivated by incubation in a solution of $20 \%$ methanol, $0.2 \%$ Triton X-100, and $1.5 \%$ hydrogen peroxide for 15 min. Sections were then processed by immunocytochemistry for Fos protein. Briefly, sections were incubated in rabbit anti-Fos antibody (Oncogene Sciences, supplied by Cambridge Biosciences, U.K. 1:1000, for $24 \mathrm{hr}$ at $4^{\circ} \mathrm{C}$ ) and then goat anti-rabbit IgG-peroxidase complex (Vector Laboratories, Peterborough, U.K., 1:500, for $24 \mathrm{hr}$ at $4^{\circ} \mathrm{C}$ ). Immunoreactivity was visualized using the Ni-glucose oxidase-DAB method (Shu et al., 1988, chemicals from Sigma) and the sections were finally dehydrated in ethanol and xylene, mounted in DPX (BDH, Glasgow, U.K.) and coverslipped. Fos-containing neuronal nuclei in the SON were counted at $10 \times$ (objective) magnification. The number of Fos-positive nuclei/mm $\mathrm{m}^{2}$ SON was quantified using computer-assisted image analysis to measure the areas of SON sections. Counts were made on at least six SON sections per rat.

\section{Experiment 2. The effect of opioid antagonists on oxytocin release within the $S O N$}

Female Sprague-Dawley rats were housed under standard conditions in Calgary (Neumann et al., 1994). Rats were mated overnight with sexually experienced males and pregnancy confirmed by the presence of sperm in vaginal smears taken the following morning (day 0 of pregnancy). On the day before the experiment each rat was anesthetized with pentobarbitone (Somnotol, MTC Pharmaceuticals, Cambridge, Ontario; $4.5 \mathrm{mg} / 100 \mathrm{gm}$, i.p.) and had a microdialysis probe (molecular cut-off $6 \mathrm{kDa}$; Landgraf, Ludwig, 1990) filled with artificial cerebrospinal fluid (aCSF) immediately before implantation, fitted stereotaxi- cally with its U-shaped tip within the right SON (1.1 mm caudal to bregma, $1.8 \mathrm{~mm}$ lateral to the midline, and $9.3 \mathrm{~mm}$ below the surface of the skull; see Paxinos and Watson, 1982). The probes were secured in place with stainless steel screws and dental cement and the rats were housed singly after recovery from surgery.

On the day of the experiment the inflow tube of the implanted probe was connected to an infusion pump via 20 -gauge tubing long enough to allow the rat free mobility. The microdialysis probes were perfused with aCSF at $3.9 \mu \mathrm{l} / \mathrm{min}$ for at least $30 \mathrm{~min}$ before sampling. Conscious virgin rats and rats on days 10,18 , and 21 of pregnancy each had three consecutive 30 min samples collected; before starting the second perfusion period either vehicle $(0.9 \%$ saline, $0.5 \mathrm{ml} / \mathrm{kg}, n=6,6,8,7$, respectively) or naloxone $(5 \mathrm{mg} / \mathrm{kg}, n=7,7,8,9$, respectively) was injected subcutaneously. Another group of $21 \mathrm{~d}$ pregnant rats was injected subcutaneously with norBNI ( $1 \mathrm{mg} / \mathrm{kg}, n=6)$. After completion of each experiment, direct osmotic stimulation (with $1 \mathrm{M} \mathrm{NaCl}$ aCSF over one $30 \mathrm{~min}$ period) via the microdialysis probe was used to verify both the placement of the probe ante mortem and the ability of the nucleus to respond to a local osmotic stimulus. Only data from rats which showed an increase in oxytocin release in the SON in response to this test were included in the results (Neumann et al., 1993b). Rats were killed by an overdose of pentobarbitone, their brains were removed and fixed in formaldehyde, and placement of the probe was verified histologically in $60 \mu \mathrm{m}$ Vibratome serial frontal sections. Dialysates were lyophilized and their oxytocin content measured without extraction by a sensitive and specific radioimmunoassay (Neumann et al., 1993b). The minimal detection limit was $0.1 \mathrm{pg} / \mathrm{sample}$ and the intra- and interassay coefficients of variation were between 7 and 10\% and 9 and $13 \%$, respectively. The in vitro relative recovery of the probe tested with ${ }^{125} \mathrm{I}$-oxytocin dissolved in aCSF and at $37^{\circ} \mathrm{C}$ was $1.7 \pm 0.2 \%$ (Neumann et al., 1993a,b).

\section{Experiment 3. The effect of naloxone on the cholecystokinin stimulated pathway to oxytocin neurons in pregnancy}

Intravenous cholecystokinin acts on the gastric vagus stimulating a neural pathway to the nucleus of the tractus solitarius (NTS) in the brainstem and, via A2 neurons, stimulates oxytocin but not vasopressin neurons to increase their firing rate and secretion (Olson et al., 1992). We used this selective stimulus to activate oxytocin neurons in pregnancy.

Firing rate. Female Wistar rats from the Babraham colony were used They were given food and water ad libitum and housed according to standard conditions in Cambridge (Leng et al., 1991). Rats were mated overnight with sexually experienced males and pregnancy was confirmed by the presence of sperm in vaginal smears taken the following morning (day 0 of pregnancy); the experimental groups were virgin ( $n$ $=8), 16 \mathrm{~d}(n=7)$, and $21 \mathrm{~d}(n=6)$ pregnant age-matched rats. Rats were anesthetized with urethane (ethyl carbamate, Sigma, Poole, U.K., $1.25 \mathrm{gm} / \mathrm{kg}$; i.p.), a jugular vein and the trachea cannulated and the SON and neural stalk exposed by ventral surgery as described previously (Leng, 1980). The activity of single neurons in the SON was recorded extracellularly using a glass micropipette filled with $0.15 \mathrm{M}$ $\mathrm{NaCl}$ introduccd into the SON by direct visual control; all recorded neurons were identified antidromically as projecting to the neural stalk. Phasically active (putative vasopressin) neurons were not tested. All continuously active neurons recorded were identified as oxytocin neurons by a positive response to intravenous injection of $20 \mu \mathrm{g} / \mathrm{kg}$ cholecystokinin octapeptide (sulfated) (CCK, Peninsula Laboratories, St. Helens, U.K.; Leng et al., 1991). One neuron from each rat was recorded through two injections of CCK $(20 \mu \mathrm{g} / \mathrm{kg})$, separated by a minimum of $30 \mathrm{~min}$. At least $20 \mathrm{~min}$ after the first injection of CCK, naloxone (naloxone hydrochloride, Sigma, $2 \mathrm{mg} / \mathrm{kg}, 4 \mathrm{mg} / \mathrm{ml}$ ) was injected intravenously; the second CCK injection was 10 min later. Spikes were discriminated with conventional equipment, and firing rates calculated on line in $60 \mathrm{sec}$ bins using SPIKE2 software (Cambridge Electronic Design, Cambridge, U.K.) and expressed as spikes/sec (Fig. 4).

Oxytocin secretion. Female Sprague-Dawley rats were mated as in Experiment 1 . On the morning of the experiment, virgin and $21 \mathrm{~d}$ pregnant age-matched rats were anesthetized with urethane, as above, and a femoral arterial cannula filled with heparinized saline $(50 \mathrm{U} / \mathrm{ml}$, Multiparin, from CP Pharmaceuticals Ltd. Wrexham, U.K., in $0.9 \% \mathrm{NaCl}$ ) inserted for blood sampling and a femoral vein cannula inserted for drug injection and reinfusion of blood cells. Two hours after surgery all rats received an intravenous drug protocol consisting of: CCK $(20$ $\mu \mathrm{g} / \mathrm{kg}), 45 \mathrm{~min}$ later naloxone $(2 \mathrm{mg} / \mathrm{kg})$ or vehicle $(0.9 \%$ saline, 0.5 $\mathrm{ml} / \mathrm{kg})$, and after another $20 \mathrm{~min}$ CCK $(20 \mu \mathrm{g} / \mathrm{kg})$ again; a similar 

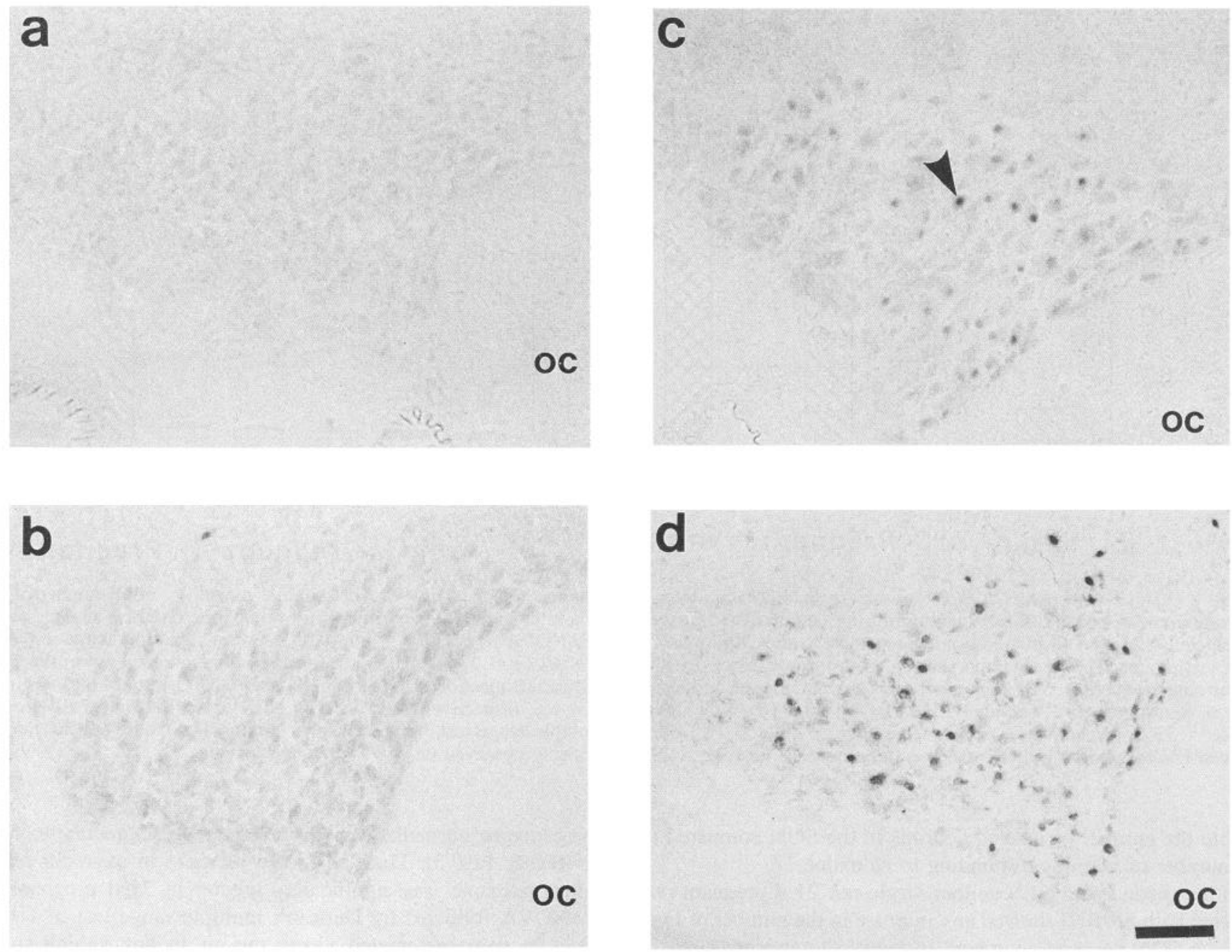

Figure 1. Photomicrographs of Fos immunoreactive nuclei in the SON of naloxone-treated pregnant and virgin rats. Hypothalamic sections containing SON were immunocytochemically stained for Fos protein. A Fos-positive cell nucleus (see arrowhead) indicates that the neuron has been activated (Hamamura et al., 1991). a, Naloxone-injected (NLX, $5 \mathrm{mg} / \mathrm{kg}, 0.5 \mathrm{ml} / \mathrm{kg}$, i.p.) virgin rat; $b$, vehicle-injected (VEH, $0.9 \%$ saline) 21 d pregnant rat; $c$, NLX-injected $21 \mathrm{~d}$ pregnant rat; $d, 1.5 \mathrm{M} \mathrm{NaCl}$-injected virgin rat (positive control). $O C$, Optic chiasm. Naloxone induced Fos immunoreactivity in SON neurons of late pregnant rats. Scale bar, $100 \mu \mathrm{m}$.

protocol to that of the experiment recording oxytocin neuron firing rate (see above). There were four groups: virgin $(n=6)$ and $21 \mathrm{~d}$ pregnant $(n=8)$ rats receiving treatment according to the $\mathrm{CCK} /$ naloxone/CCK protocol and virgin $(n=6)$ and 21 d pregnant $(n=8)$ rats receiving treatment according to the CCK/vehicle/CCK protocol. Ten blood samples each of $300 \mu \mathrm{l}$ were taken over $90 \mathrm{~min}$ as follows: $10 \mathrm{~min}, 5 \mathrm{~min}$, and immediately before the first CCK dose, $5 \mathrm{~min}$ and $45 \mathrm{~min}$ after CCK (the last immediately before naloxone or vehicle), $10 \mathrm{~min}, 15 \mathrm{~min}$, and $20 \mathrm{~min}$ after the naloxone/vehicle (the last immediately before the second CCK dose) and finally $5 \mathrm{~min}$ and $15 \mathrm{~min}$ after the second CCK dose (see Fig. 5). Blood samples were immediately centrifuged, the plasma separated and frozen, and the red blood cells resuspended in $150 \mu \mathrm{l}$ of $0.9 \%$ saline and reinfused intravenously. Oxytocin concentrations in unextracted plasma were quantified by radioimmunoassay using the Higuchi antiserum (kindly supplied by Dr. T. Higuchi, Kochi Medical School, Kochi, Japan; Higuchi et al., 1986); the assay included a second antibody step (donkey anti-rabbit serum, 1:100, Gamma B, IDS, Tyne and Wear, U.K.) to precipitate the first antibody complex and the use of standardized Pansorbin cells (Novabiochem (U.K.) Ltd. Nottingham, U.K., $0.4 \% \mathrm{w} / \mathrm{v}$ solution in phosphate buffer) to aid visualization of the precipitate; supernatants were then aspirated before precipitates were counted in a gamma scintillation counter (LKB-Wallac 1272 Clinigamma). The intra-assay coefficients of variation were 10 and $11 \%$ at concentrations of 20 and $100 \mathrm{pg} / \mathrm{ml}$, respectively, and all samples were assayed at the same time.

\section{Statistics}

Data are presented as means \pm SEM and were compared using analysis of variance (ANOVA) between groups, ANOVA for repeated measures, $t$ tests and paired $t$ tests, or nonparametric equivalents as appropriate, performed with NUMBER CRUNCHERS statistical software.

\section{Results}

The effect of opioid antagonists on SON neuron Fos expression in pregnancy

In the first study, (1) compared with both the naloxone-injected virgin rats and the vehicle-injected pregnant rats on day 21 of pregnancy naloxone in $21 \mathrm{~d}$ pregnant rats induced a significantly greater number of Fos-positive nuclei in the SON $(+417 \%$ and $+243 \%$ respectively, ANOVA, $p<0.001$, followed by Duncan's multiple range test, Figs. $1 a-c, 2 a$ ) these tended to be located in the dorsal, oxytocin-rich area of the SON. There was no significant difference between naloxone-injected virgin rats and vehicle-injected pregnant rats. Positive control rats injected intraperitoneally with $1.5 \mathrm{M} \mathrm{NaCl}$ showed numerous Fos-positive nuclei throughout the SON (Figs. 1d, 2a) with more than 
<smiles>[CH]C=[Co]</smiles>

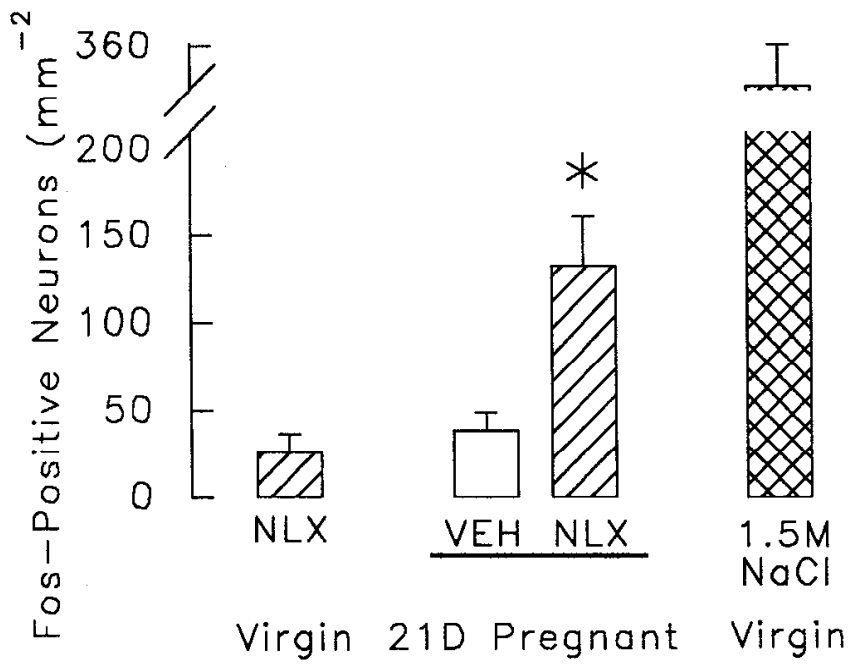

b)

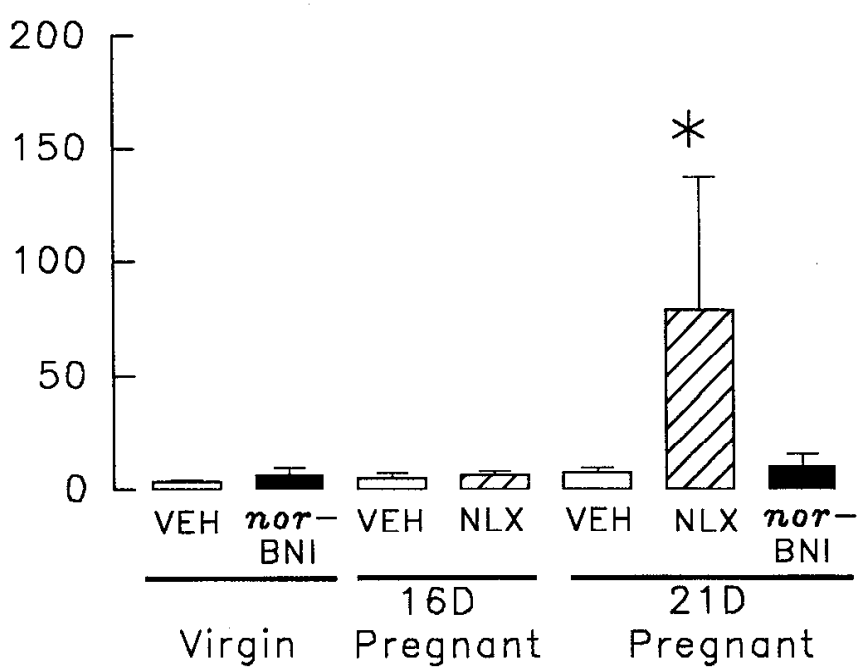

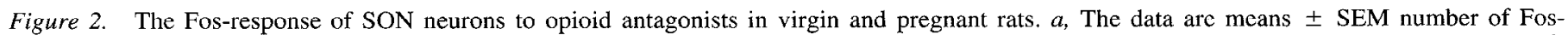

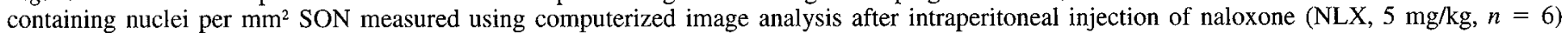

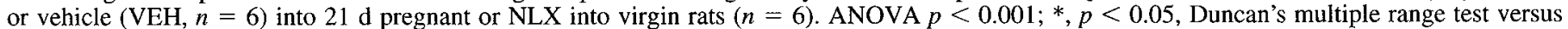

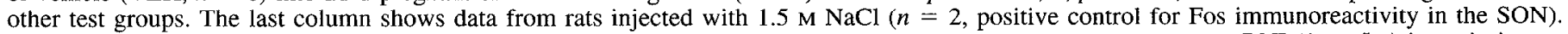

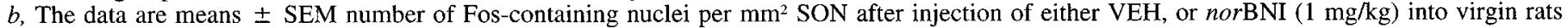

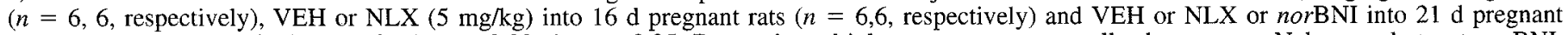

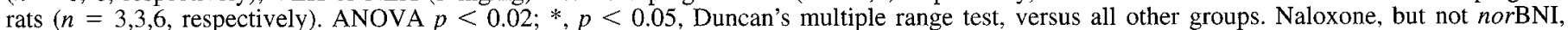
induced Fos expression in SON magnocellular neurons, and the response was only observed on day 21 of pregnancy.

double the number of labeled neurons in the SON compared to the number of neurons responding to naloxone.

In the second study, (2) neither virgin nor $21 \mathrm{~d}$ pregnant rats injected with norBNI showed any increase in the number of Fospositive SON neurons compared to vehicle treatment (Fig. 2b) and there was no difference between the virgin and pregnant groups. Naloxone did not increase the numbers of Fos-positive nuclei in $16 \mathrm{~d}$ pregnant rats compared to vehicle (Fig. 2b). The mean number of Fos-positive nuclei $/ \mathrm{mm}^{2} \mathrm{SON}$ in naloxonetreated $21 \mathrm{~d}$ pregnant rats was significantly greater than in all other groups (ANOVA, $p<0.02$, followed by Duncan's multiple range test) confirming the significant effect of naloxone in the initial study (Fig. 2a).

\section{The effect of opioid antagonists on oxytocin release within the} SON

Basal oxytocin release within the SON was $0.91 \pm 0.15 \mathrm{pg} / 30$ min in the virgin group (all rats, $n=13$ ) before treatment and there was no significant difference in basal release between the virgin and any of the pregnant rat groups (days 10, 18, 21, respectively, $1.61 \pm 0.34, n=13 ; 0.81 \pm 0.14, n=16 ; 1.10 \pm$ $0.15, n=22, \mathrm{pg} / 30 \mathrm{~min}$, ANOVA). Naloxone did not have any effect on intranuclear oxytocin release in virgin or $10 \mathrm{~d}$ pregnant rats in either the first or second sampling period postinjection. Only on days 18 and 21 of pregnancy did naloxone significantly increase total oxytocin content of the postinjection dialysate sample compared to the respective preinjection sample (1.7 and 2.6-fold, respectively, ANOVA for repeated measures followed by Tukey's protected $t$ test, $p<0.05$ ). norBNI had no significant effect on oxytocin release within the SON in the $21 \mathrm{~d}$ pregnant group (ANOVA for repeated measures followed by Tukey's protected $t$ test, Fig. $3 d$ ). The data are presented graphically as percentages normalized to their respective pretreatment values $(=100 \%$, Fig. 3). The percentage increase in oxytocin release after naloxone was significantly greater in $21 \mathrm{~d}$ pregnant rats (ANOVA followed by Duncan's multiple range test $p<0.05$ ) than in naloxone-treated virgin rats or in any vehicle-treated group (Fig. 3d).

\section{The effect of naloxone on the electrical activity of oxytocin neurons in pregnancy}

Mean basal firing rate of identified oxytocin neurons was not significantly different between groups $(2.46 \pm 0.51,4.14 \pm$ 0.84 , and $2.94 \pm 0.81$ spikes/sec in virgin, $16 \mathrm{~d}$ pregnant, and $21 \mathrm{~d}$ pregnant rats, respectively). The responses of each cell were quantified by subtracting the mean basal firing rate per min (over $10 \mathrm{~min}$ ) from the firing rate per min postinjection (over a 10 min period). Total excess spikes over $10 \mathrm{~min}$ postinjection were then summed and change in firing rate in spikes/sec calculated. Group mean changes in firing rate were then calculated.

In virgin rats, cells responded to the first injection of CCK with a mean increase in firing rate of $0.88 \pm 0.11 \mathrm{spikes} / \mathrm{sec}$ averaged over the $10 \mathrm{~min}$ after injection (see also Fig. $4 a$ ). Twenty minutes after CCK the firing rate had returned to original control levels. Effects of systemically administered naloxone against exogenous opioid actions are maximal hetween 5 and 10 min postinjection (Bicknell et al., 1988). Comparing the firing rate of the oxytocin cells in this period after naloxone injection to the preinjection control rate, naloxone produced a mean change of $+0.1 \pm 0.15$ spikes/sec (NS). Following naloxone, the neuronal response to a second injection of CCK was similar to the initial response; firing rate increased by $0.79 \pm 0.11$ spikes/sec (Fig. $4 a$ ). For each cell the ratio of the responses to the two injections of CCK (CCK2:CCK1) was calculated; after 
a) VIRGIN
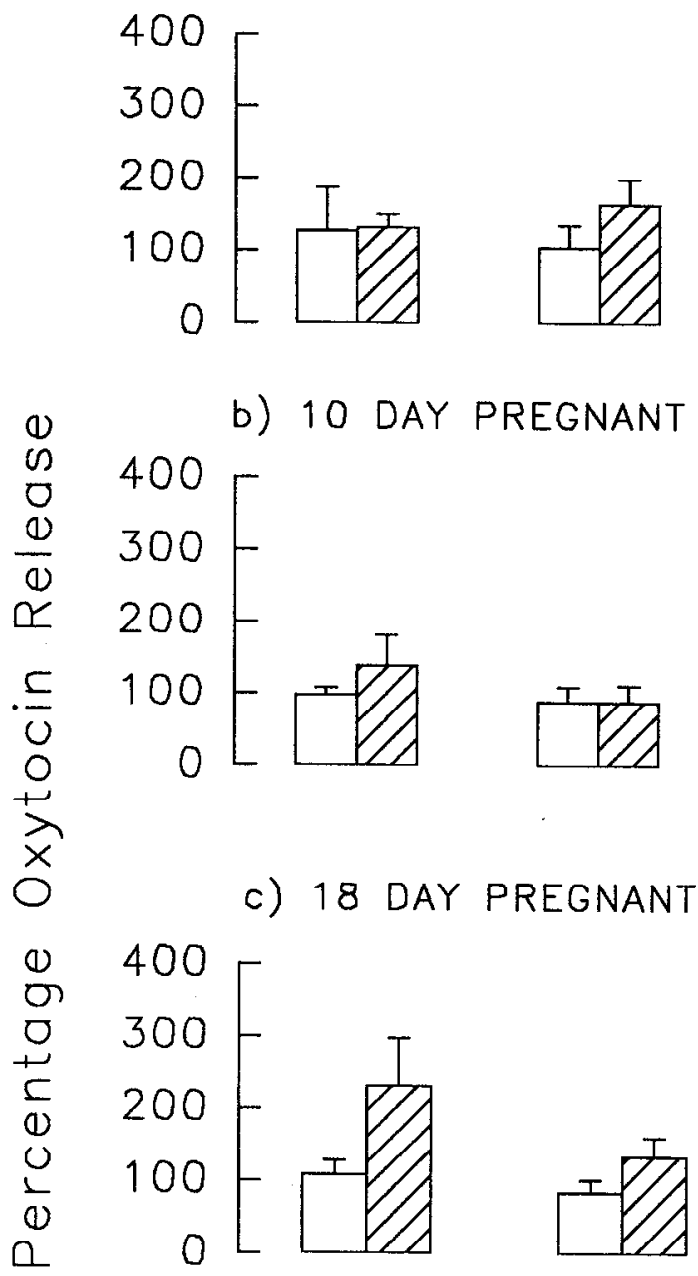

d) 21 DAY PREGNANT

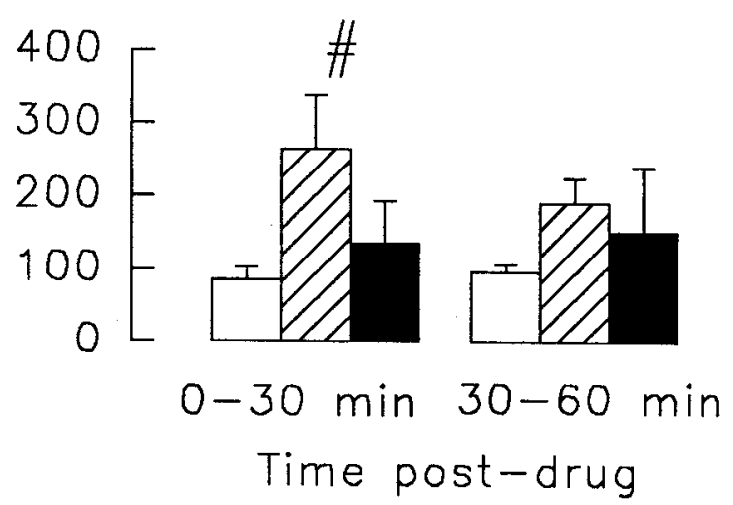

Figure 3. Oxytocin release within the SON in response to opioid antagonists in virgin and pregnant rats. Oxytocin release in the SON measured by microdialysis over two 30 min periods after subcutaneous injection of vehicle (VEH, $\square$ ), naloxone (NLX, 圈), or norBNI ( $\square, 21 \mathrm{~d}$ only). The data are expressed as the means \pm SEM percentage of the basal release for each group before drug injection, in virgin $(n=6,7$, respectively), $10 \mathrm{~d}$ pregnant $(n=6,7), 18 \mathrm{~d}$ pregnant $(n=8,8)$, and 21 d pregnant rats $(n=7,9,6)$. \#, $p<0.05$ (ANOVA, followed by Duncan's multiple range test) for percentage increase in release in first post drug sample versus all VEH-injected groups and versus NLX-injected virgin rats. Only in late pregnancy did naloxone increase oxytocin release within the SON; the $\kappa$-opioid antagonist had no effect. a) VIRGIN

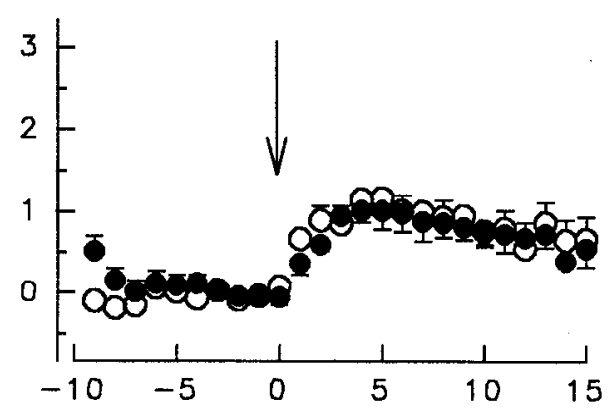

b) 16 DAY PREGNANT

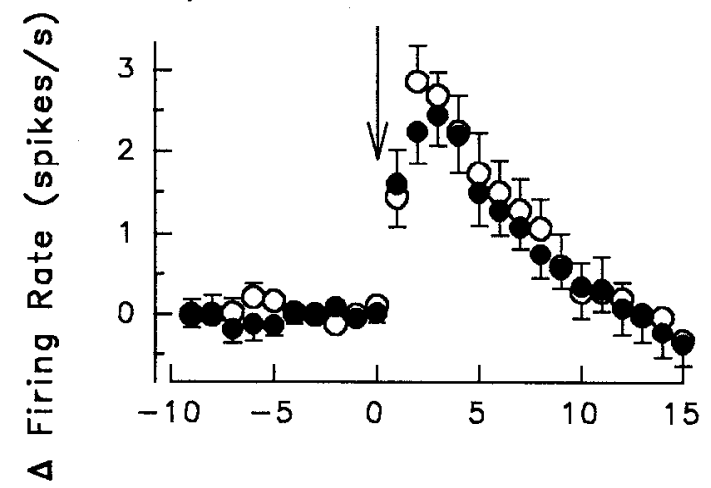

c) 21 DAY PREGNANT

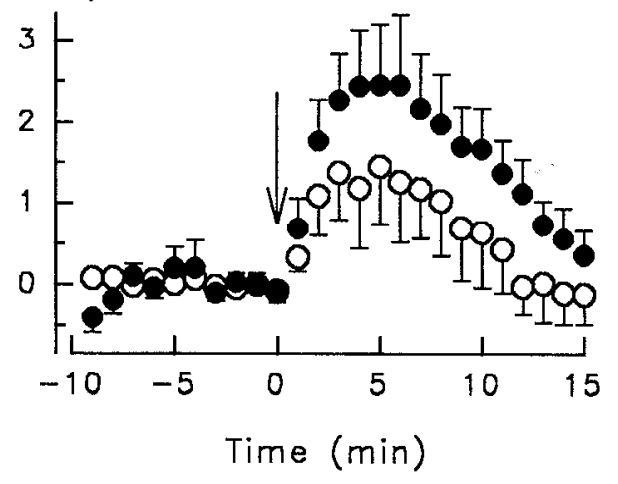

Figure 4. Oxytocin neuron firing rate responses to $\mathrm{CCK}$ and naloxone. The data represent the means \pm SEM of change in firing rate (spikes/sec) of identified oxylocin neurons conpared to the average firing rate over the previous $10 \mathrm{~min}$ in anesthetized: $a$, virgin rats, $n=$ $8 ; b, 16 \mathrm{~d}$ pregnant rats, $n=7$; and $c, 21 \mathrm{~d}$ pregnant rats, $n=6$ after administration of CCK (at arrow; $20 \mu \mathrm{g} / \mathrm{kg}$ ) with (O) or without $(\bigcirc)$ naloxone pretreatment $(2 \mathrm{mg} / \mathrm{kg})$. Naloxone potentiated the firing rate response to CCK in $21 \mathrm{~d}$ pregnant rats only.

naloxone the mean CCK2:CCK1 ratio was $0.93 \pm 0.13$ and was not significantly different from unity.

In $16 \mathrm{~d}$ pregnant rats oxytocin cells responded to $\mathrm{CCK}$ with an increase in firing rate of $1.63 \pm 0.27$ spikes $/ \mathrm{sec}$ averaged over 10 min (not significant vs either virgin or $21 \mathrm{~d}$ pregnant rats, ANOVA). However, the immediate response over $5 \mathrm{~min}$ $(2.19 \pm 0.35$ spikes $/ \mathrm{sec})$ was significantly greater than the response in both virgin $(0.92 \pm 0.07$ spikes/sec $)$ and $21 \mathrm{~d}(1.09$ \pm 0.47 spikes $/ \mathrm{sec})$ pregnant rats $(p<0.01$, ANOVA followed by Duncan's multiple range test). Following naloxone their 
(a) VIRGIN

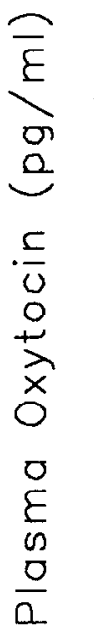

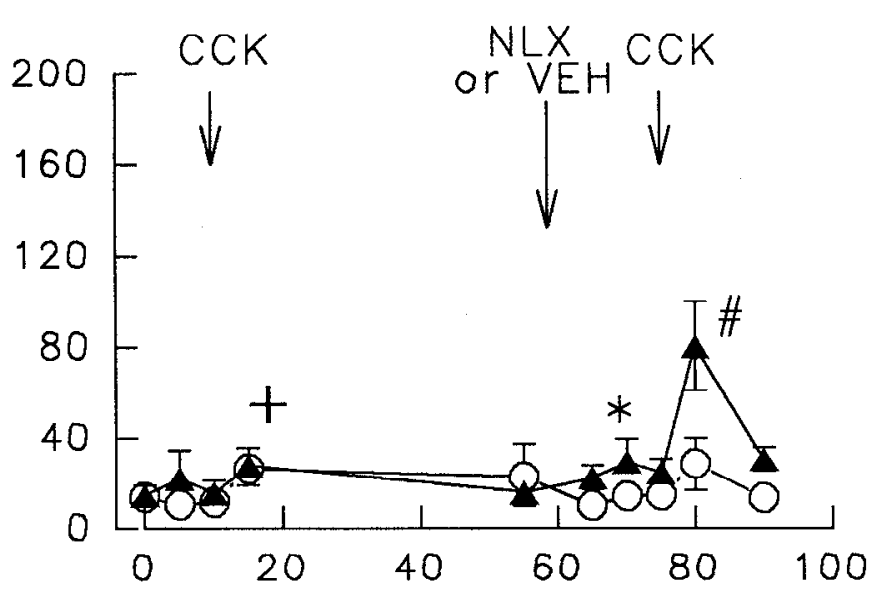

(b) 21 DAY PREGNANT

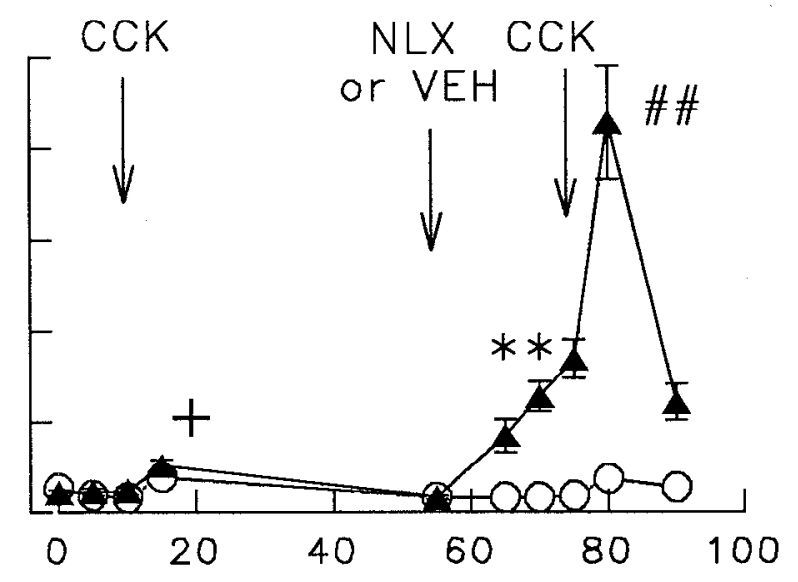

\section{Time (min)}

Figure 5. The oxytocin secretory response to CCK and naloxone in pregnant and virgin rats. The data represent the means \pm SEM of plasma oxytocin concentration in arterial blood samples taken before and after the administration of CCK $(20 \mu \mathrm{g} / \mathrm{kg})$ then vehicle (VEH) then CCK $(\mathrm{O})$ or CCK then naloxone (NLX, $2 \mathrm{mg} / \mathrm{kg}$ ) then CCK $(\boldsymbol{\Delta})$ as described in Materials and Methods, from anesthetized: $a$, virgin rats $(n=6$, 6 , respectively); and $b, 21$ d pregnant rats $(n=8,8$, respectively).,$+ p<0.05$, CCK response versus preinjection sample in any group, Wilcoxon Rank Sum Test; *, $p<0.05 ; * *, p<0.001$, NLX response versus VEH, Mann-Whitney $U$ test; \#, $p<0.05$; \#\#, $p<0.001$, CCK response in NLX versus VEH-treated rats, Mann-Whitney; $p<0.05$, CCK response in NLX-treated pregnant rats versus NLX-treated virgin rats. In $21 \mathrm{~d}$ pregnant rats the systemic oxytocin secretory response to CCK after naloxone was significantly greater than that in virgin rats.

background activity changed by $+0.10 \pm 0.25$ spikes/sec (NS). They responded to the second CCK injection with an increase of $1.32 \pm 0.25$ spikes $/ \mathrm{sec}$ (averaged over $10 \mathrm{~min}$, Fig. $4 b$ ). Using data collected over $10 \mathrm{~min}$, the CCK2:CCK1 ratio was $0.85 \pm 0.14$, which was not significantly different from unity or from the ratio in virgin rats, but significantly lower than in 21 d pregnant rats ( $p<0.001$; ANOVA).

In $21 \mathrm{~d}$ pregnant rats oxytocin cells responded to CCK with an increase of $1.08 \pm 0.53$ spikes/s (see also Fig. $4 c$ ), not different from virgin rats. Although naloxone increased the basal firing rate in four out of the six cells, the overall mean change for the six cells of $+0.36 \pm 0.20$ spikes/sec was not significant. The response to a subsequent injection of $\mathrm{CCK}$ was potentiated in all cells; the mean response, averaged over $10 \mathrm{~min}$, was an increase of $1.74 \pm 0.57$ spikes/sec (Fig. $4 c$ ), with a CCK2: CCK 1 ratio of $2.08 \pm 0.38$, significantly greater than unity and than the corresponding ratios in virgin and $16 \mathrm{~d}$ pregnant rats ( $p<0.001$, ANOVA followed by Duncan's multiple range test). Thus, only in $21 \mathrm{~d}$ pregnant rats did naloxone potentiate the oxytocin neuron firing rate response to $\mathrm{CCK}$.

The effect of naloxone on the CCK-induced increase in oxytocin secretion in pregnancy

Overall, taking the mean of the first three basal samples from all animals, the plasma oxytocin concentration in virgin rats was not significantly different from that in the $21 \mathrm{~d}$ pregnant rats (Mann-Whitney $U$ test, $14.5 \pm 4.2 \mathrm{pg} / \mathrm{ml}, n=12$ vs $8.5 \pm$ $2.2 \mathrm{pg} / \mathrm{ml}, n=16$, respectively). The oxytocin secretory response to the first intravenous CCK injection in all virgin animals was similar to that in all $21 \mathrm{~d}$ pregnant animals (both $p<$ 0.05 vs preinjection, Wilcoxon rank sum test, Fig. $5 a, b)$. In virgin rats naloxone caused a small significant increase (1.7-fold) in plasma oxytocin concentration compared to vehicle-treated virgin rats ( $p<0.05$, Mann-Whitney) and the second injection of CCK induced a further significant rise $(2.8$-fold, $p<0.05$, Mann-Whitney, Fig. $5 a$ ). In 21 d pregnant rats naloxone caused a large 9.7-fold increase in plasma oxytocin concentration compared to preinjection and to vehicle-treated pregnant rats $(p<$ 0.02 , Wilcoxon, and $p<0.001$, Mann-Whitney, respectively, Fig. $5 b$ ). The oxytocin secretory response to the second injection of CCK (after naloxone) was greatly potentiated compared to the increase after vehicle (13.9-fold increase, $p<0.001$, MannWhitney, Fig. $5 b$ ), and was significantly higher than that in the naloxone-treated virgin rats $(p<0.05$, Mann-Whitney).

\section{Discussion}

The present study demonstrates that, at the end of pregnancy, endogenous opioid systems dynamically restrain the central activity of oxytocin neurons, and as a consequence, secretion of oxytocin from the neurohypophysis. These opioid systems act in part by suppressing the responsiveness of oxytocin neurons to afferent stimulation. The administration of naloxone at the end of pregnancy resulted in activation of Fos expression in supraoptic neurons and resulted in increased oxytocin release within the supraoptic nucleus, probably reflecting increased electrical activity of these neurons at this time. Naloxone also potentiated oxytocin neuron firing rate responses to stimulation of an input pathway (using CCK). Mcasurements of oxytocin secretion into the plasma following injections of $\mathrm{CCK}$ and naloxone confirmed the naloxone facilitation of afferent stimulation. In all cases the effects were selectively observed in late pregnancy.

Oxytocin neurons express Fos in response to a variety of stimuli such as parturition (Luckman et al., 1993) or intravenous CCK (Hamamura et al., 1991) both of which transiently increase the firing rate of oxytocin neurons. Recent studies have shown 
that transsynaptic activation is most likely required for induction of Fos in magnocellular neurons (Luckman et al., 1994). Whereas continuous suckling, another stimulus for oxytocin secretion, does not induce Fos (Fenelon et al., 1993) resuckling after removal of pups for $48 \mathrm{hr}$ can induce Fos in SON neurons (Smith et al., 1994). So induction of Fos in oxytocin neurons may be taken to indicate excitatory synaptic activation. Therefore, from the data presented in Figure 2, endogenous opioids are likely to be preventing synaptic activation of oxytocin neurons in late pregnancy.

Naloxone acts at all opioid receptor types, although with a higher affinity for the $\mu$-type (Kosterlitz, 1985). To investigate whether the endogenous opioid(s) which inhibit oxytocin neurons were mediated via $\mu$ - or $\kappa$ - receptors, both of which are found in the SON (Sumner ct al., 1992), we also uscd a specific $\kappa$-opioid antagonist, norBNI. Despite using a dose of norBNI which has previously been shown to reverse the inhibitory effects of U50,488 (a selective $\kappa$-agonist, at its ED50 of 0.5 $\mathrm{mg} / \mathrm{kg}$ ) on oxytocin neuron firing rate (Pumford et al., 1993) and on parturition (Douglas et al., 1993a), norBNI did not increase the number of Fos-positive neurons in the SON in pregnant rats suggesting that endogenous $\kappa$-opivids do not contribute to the central inhibition of oxytocin neurons in pregnancy. $\mu$-Opioid receptor binding in the SON is decreased by day 21 of pregnancy but $\kappa$ - binding remains unaltered (Sumner et al., 1992), also indicating dynamic $\mu$-rather than $\kappa$-mechanisms in pregnancy.

Oxytocin release within the SON was also shown to be inhibited by endogenous opioids but not via $\kappa$-receptors, whereas release from the neural lobe is inhibited via $\kappa$ - rather than $\mu$-receptors (Bunn et al., 1985; Herkenham et al., 1986). Oxytocin release within the SON has been found previously in many circumstances in which oxytocin neuron firing rate increases, including during parturition and suckling (Moos et al., 1989; Neumann et al., 1993b). Release is likely to be mainly from the dendrites of magnocellular neurons (Pow and Morris, 1989), and possibly their cell bodies and recurrent axon collaterals, and may be regulated independently from neuron firing rate and peripheral secretion. Nonetheless, oxytocin release within the SON is under endogenous opioid inhibition during late pregnancy; although this inhibition is later removed during parturition (Neumann et al., 1993b). Oxytocin receptor binding has been demonstrated in the SON (Freund-Mercier and Stoeckel, 1993) and oxytocin release within the SON plays a positive role in the autoregulation of oxytocin neurons (Moos et al., 1984), coordinating synchronous firing of neurons which precedes the release of a bolus of oxytocin into the blood in parturition (Summerlee, 1981). Progress of parturition is delayed by administration of oxytocin antagonist into the SON (Russell et al., 1994) therefore release of oxytocin within the SON plays an essential role in labor. Thus intranuclear oxytocin release is held at a low level by endogenous opioids in late pregnancy prior to when it is required during parturition.

The noradrenergic projection from the A2 cell group provides a direct excitatory input to the oxytocin cells (Raby and Renaud, 1989) and these neurons also express Fos during spontaneous parturition (Luckman et al., 1993), when they are likely to receive signals from the contracting uterus. Intravenous CCK activates oxytocin neurons via a noradrenergic projection from the A2 cell group in the NTS. Thus CCK induces Fos expression in adrenergic neurons in the NTS (Luckman, 1992) and induces noradrenaline release within the SON and PVN (Kendrick et al.,
1991). In addition, iontophoretically-applied adrenergic antagonists block the firing rate response of oxytocin cells in the PVN to CCK (Ueta et al., 1993) and pretreatment with neurotoxins which selectively deplete hypothalamic noradrenaline content block the release of oxytocin in response to CCK (Onaka et al., 1995a). We have used CCK to stimulate this excitatory pathway to investigate whether endogenous opioids also inhibit synaptically driven oxytocin neuron function.

The endogenous opioid mechanism which we have now shown to emerge at the end of pregnancy appears to act at $\mu$-receptors. Thus the endogenous opioid is likely to act at the same receptors at which $\mu$-opiates act, for example morphine. Morphine restrains the release of oxytocin in response to CCK at least in part by a presynaptic inhibition of noradrenaline release (Onaka ct al., 1995b). Since morphine does not prevent the CCK-induced expression of Fos in the NTS, it therefore appears not to significantly inhibit the activity of the noradrenergic cell bodies (Onaka et al., 1995b). Similarly morphine does not inhibit the expression of Fos in the NTS during parturition (Luckman et al., 1993), although in both cases it prevents the expression of Fos in the SON. Therefore since naloxone increases stimulated (via the NTS inpul) oxylocin neuron firing rate and secretion, the endogenous opioids appear to inhibit oxytocin neurons by a presynaptic action. Central endogenous opioid inhibition of oxytocin neurons was not observed on day 16 of pregnancy when the oxytocin neuron firing rate response to CCK was greater than in virgin rats (Fig. 4). This suggests that there is an increase in the coupling of the NTS noradrenergic pathway, excited by CCK, to oxytocin neurons on day 16 of pregnancy. Such an increase in oxytocin neuron responsiveness is then masked by the endogenous opioid inhibition (becoming obvious after day 16 and before day 21 of pregnancy), giving an apparent reduction in the oxytocin neuron firing rate response to $\mathrm{CCK}$ at this time.

We have previously shown that, in contrast to the present results, there appears to be no central opioid restraint of oxytocin secretion in response to either systemic hyperosmotic stimulation or to electrical stimulation of the lamina terminalis (involved in osmotic responses of SON neurons) at the end of pregnancy. Indeed, after naloxone, electrical stimulation of the lamina terminalis or systemic hyperosmolarity is less effective in pregnant than in virgin rats (Bull and Russell, 1992; Bull et al., 1994). Therefore, removal of endogenous opioid inhibition on oxytocin neurons at the end of pregnancy will selectively increase the excitatory influence of the input from the brainstem. This stimulus-selective modulation of oxytocin neuron activity in late pregnancy strongly suggests that the endogenous opioids act selectively upon particular inputs rather than on the final common pathway - the oxytocin neurons. Our present findings that naloxone potentiated the CCK-induced increase in firing rate but did not significantly increase the basal firing rate further suggests action only presynaptically. Furthermore, $\mu$-opioid receptor mRNA is present in the NTS but is sparse in the SON and PVN (Minami et al., 1994), consistent with opioid receptors in the SON being located on the nerve terminals of afferents.

The endogenous opioid $\beta$-endorphin, which acts at $\mu$-receptors and is synthesized from proopiomelanocortin (POMC) in the arcuate nucleus, may be involved in the restraint of oxytocin neurons described above. During late pregnancy, both hypothalamic content and plasma concentration of $\beta$-endorphin increase (Wardlaw and Frantz, 1983; Dondi et al., 1991) and we have found the number of arcuate neurons expressing POMC mRNA 
(unpublished observations) increases, whereas neither prodynorphin (Douglas et al., 1993b) nor proenkephalin A mRNA (Douglas and Russell, 1994) alter in magnocellular or parvocellular neurons of the SON and PVN at this time. Such opioid mechanisms may be induced by the ovarian hormones of pregnancy, relaxin or progesterone, and we have shown that both can influence opioid inhibition of oxytocin neurons (Way and Leng, 1992; Way et al., 1993).

In conclusion, we now ascribe the strong endogenous opioid inhibition of oxytocin neurons at the end of pregnancy to centrally acting opioids, mediated by $\mu$-receptors. Antagonism of this opioid restraint in conscious late pregnant rats stimulates the $c$-fos gene and increases oxytocin release within the SON, as well as increasing oxytocin secretion into the blood. We were able to confirm this in ancsthetized rats by using CCK to activate a brainstem pathway to oxytocin neurons, showing that this pathway is more effective at the end of pregnancy after antagonizing the endogenous opioid restraining it. Therefore, the data imply that endogenous opioids inhibit oxytocin neurons presynaptically by regulation of noradrenaline release. The central opioid inhibition of oxytocin neurons at the end of pregnancy may allow enhanced coupling of brainstem excitatory inputs which will reflexly drive oxytocin secretion in parturition, and prevent premature secretion of oxytocin until the opioid restraint is lifted, at least partially, at the onset of parturition.

\section{References}

Bicknell RJ, Leng G, Lincoln DW, Russell JA (1988) Naloxone excites oxytocin neurones in the supraoptic nucleus of lactating rats after chronic morphine treatment. J Physiol (Lond) 396:297-317.

Brooks PJ (1992) The regulation of oxytocin mRNA levels in the medial preoptic area. Relationship to maternal behavior in the rat. Ann NY Acad Sci 652:271-285.

Bull PM, Russell JA (1992) Oxytocin secretory responses to hypernatraemia and inhibition by morphine in pregnant urethane-anaesthetized rats. J Physiol (Lond) 452:210P.

Bull PM, Douglas AJ, Russell JA (1994) Opioids and coupling of the anterior peri-third ventricular input to oxytocin neurones in anaesthetized pregnant rats. J Neuroendocrinol 6:267-274.

Bunn SJ, Hanley MR, Wilkin GP (1985) Evidence for a kappa-opioid receptor on pituitary astrocytes: an autoradiographic study. Neurosci Lett 19:55:317-323.

Clarke G, Wright DM (1984) A comparison of analgesia and suppression of oxytocin release by opiates. Br J Pharmacol 83:799-806.

Dondi D, Maggi R, Panerai AE, Piva F, Limonta P (1991) Hypotha lamic opiatergic tone during pregnancy, parturition and lactation in the rat. Neuroendocrinology 53:460-466.

Douglas AJ, Russell JA (1993) Central kappa-opioid action on supraoptic nucleus (SON) neurones during parturition in the rat. J Endocrinol Invest 16[Suppl 1-8]:200.

Douglas AJ, Russell JA (1994) Corticotrophin-releasing hormone, proenkephalin A and oxytocin mRNAs in the paraventricular nucleus during pregnancy and parturition in the rat. Gene Ther 1[Suppl 1]: S85.

Douglas AJ, Clarke G, MacMillan SJA, Bull PM, Neumann I, Way SA, Wright DM, McGrory BG, Russell JA (1993a) Effects of the kappaopioid agonist U50,488 on parturition in rats. Br J Pharmacol 109: $251-258$

Douglas AJ, Dye S, Leng G, Russell JA, Bicknell RJ (1993b) Endog. enous opioid regulation of oxytocin secretion through pregnancy in the rat. J Neuroendocrinol 5:307-314.

Douglas AJ, Johnstone LE, Leng G, Russell JA (1993c) Endogenous opioid inhibition of supraoptic nucleus (SON) oxytocin cell activity in late pregnant rats. Br J Pharmacol [Suppl] 109:101P.

Douglas AJ, Johnstone LE, Neumann I, Leng G, Kussell JA (1994a) Oxytocin neurones in the supraoptic nucleus (SON) are inhibited by endogenous opioids in late pregnant rats. Gene Ther 1[Suppl 1]:S84.

Douglas AJ, Meeren HKM, Johnstone LE, Neumann I, Russell JA (1994b) Opioid inhibition of oxytocin neurones in the rat is confined to late pregnancy and is not kappa-receptor mediated. J Physiol (Lond) 479:47P.

Fenelon VS, Poulain DA, Theodosis DT (1993) Oxytocin neuron activation and Fos expression: a quantitative immunocytochemical analysis of the effect of lactation, parturition, osmotic and cardiovascular stimulation. Neuroscience 53:77-89.

Freund-Mercier MJ, Stoeckel ME (1993) Oxytocin receptors on oxytocin neurons: histoautoradiographic detection after icv oxytocin antagonist treatment. J Endocrinol Invest 16[Suppl 1]:187.

Giovannelli L, Shiromani PJ, Jirikowski GF, Bloom FE (1992) Expression of c-fos protein by immunohistochemically identified oxytocin neurones in the rat hypothalamus upon osmotic stimulation. Brain Res 588:41-48.

Hamamura M, Leng G, Emson PC, Kiyama H (1991) Electrical activation and $\mathrm{c}$-fos mRNA expression in rat neurosecretory neurones after systemic administration of cholecystokinin. J Physiol (Lond) 444:51-63.

Hamamura M, Nunez DJ, Leng G, Emson PC, Kiyama H (1992) c-fos may code for a common transcription factor within the hypothalamic neural circuits involved in osmoregulation. Brain Res 572:42-51.

Hartman RD, Rosella-Dampman LM, Emmert SE, Summy-Long JY (1986) Inhibition of release of neurohypophysial hormones by endogenous opioid peptides in pregnant and parturient rats. Brain Res 382:352-359.

Herkenham M, Rice KC, Jacobson AE, Rothman RB (1986) Opiate receptors in rat pituitary are confined to the neural lobe and are exclusively kappa. Brain Res 382:365-371.

Higuchi T, Tadokoro Y, Honda K, Negoro H (1986) Detailed analysis of blood oxytocin levels during suckling and parturition in the rat. $\mathrm{J}$ Endocrinol 110:251-256.

Kendrick K, Leng G, Higuchi T (1991) Noradrenaline, dopamine and serotonin release in the paraventricular and supraoptic nuclei of the rat in response to intravenous cholecystokinin injections. J Neuroendocrinol 3:139-144.

Kosterlitz HW (1985) Opioid peptides and their receptors. Proc R Soc Lond [Biol] 225:27-40.

Landgraf R, Ludwig M (1990) Vasopressin release within the supraoptic and paraventricular nuclei of the rat brain: osmotic stimulation via microdialysis. Brain Res 558:191-196.

Leng G (1980) Rat supraoptic neurones: the effects of locally applied hypertonic saline. J Physiol (Lond) 304:405-414.

Leng G, Way S, Dyball RE (1991) Identification of oxytocin cells in the rat supraoptic nucleus by their response to cholecystokinin injection. Neurosci Lett 122:159-162.

Leng G, Dyball RE, Way SA (1992) Naloxone potentiates the release of oxytocin induced by systemic administration of cholecystokinin without enhancing the electrical activity of supraoptic oxytocin neurones. Exp Brain Res 88:321-325.

Leng G, Bicknell RJ, Brown D, Bowden C, Chapman C, Russell JA (1994) Stimulus-induced depletion of pro-enkephalins, oxytocin and vasopressin and pro-enkephatin interaction with posterior pituitary hormone release in vitro. Neuroendocrinology 60:559-566.

Luckman SM (1992) Fos-like immunoreactivity in the brainstem of the rat following peripheral administration of cholecystokinin. J Neuroendocrinol 4:149-152.

Luckman SM, Antonijevic I, Leng G, Dye S, Douglas AJ, Russell JA, Bicknell RJ (1993) The maintenance of normal parturition in the rat requires neurohypophysial oxytocin. J Neuroendocrinol 5:7-12.

Luckman SM, Dyball REJ, Leng G (1994) Induction of c-fos expression in hypothalamic neurons requires synaptic activation and not simply increased spike activity. J Neurosci 14:4825-4830.

Minami M, Onogi T, Toya T, Katao Y, Hosoi Y, Maekawa K, Katsumata S, Yabuuchi K, Satoh M (1994) Molecular cloning and in situ hybridisation histochemistry for rat $\mu$-opioid receptor. Neurosci Res 18 : 315-322.

Moos F, Freund-Mercier MJ, Guerne Y, Guerne JM, Stoeckel ME, Richard P (1984) Release of oxytocin and vasopressin by magnocellular nuclei in vitro: specific facilitatory effect of oxytocin on its own release. J Endocrinol 102:63-72.

Moos F, Poulain DA, Rodriguez F, Guerne $\mathrm{Y}$, Vincent JD, Richard P (1989) Release of oxytocin within the supraoptic nucleus during the milk ejection reflex in rats. Exp Brain Res 76:593-602.

Neumann I, Ludwig M, Engelmann M, Pittman QJ, Landgraf R (1993a) Simultaneous microdialysis in blood and brain: oxytocin and vaso- 
pressin release during osmotic stimulation and suckling in the rat. Neuroendocrinology 58:637-645.

Neumann I, Russell JA, Landgraf K (1993b) Oxytocin and vasopressin release within the supraoptic and paraventricular nuclei of pregnant, parturient and lactating rats: a microdialysis study. Neuroscience 53: $65-75$.

Neumann I, Porter DWF, Landgraf R, Pittman QJ (1994) Rapid effect on suckling of an oxytocin antisense oligonucleotide administered into rat supraoptic nucleus. Am J Physiol 267:R852-R858.

Olson BR, Hoffman GE, Sved AF, Stricker EM, Verbalis JG (1992) Cholecystokinin induces $c$-fos expression in hypothalamic oxytocinergic neurons projecting to the dorsal vagal complex. Brain Res 569: $238-248$.

Onaka 'T, Luckman SM, Antonijevic IA, Palmer JR, Leng G (1995a) Involvement of the noradrenergic afferents from the nucleus tractus solitarii to the supraoptic nucleus in oxytocin release after peripheral cholecystokinin octapeptide in the rat. Neuroscience, in press.

Onaka T, Luckman SM, Guevara-Guzman R, Ueta Y, Kendrick K, Leng G (1995b) Presynaptic actions of morphine: blockade of cholecystokinin-induced noradrenaline release in the rat supraoptic nucleus. $J$ Physiol (Lond) 482:69-79.

Paxinus G, Watson C (1982) The rat brain in stereotaxic coordinates. Sydney: Academic.

Pow DV, Morris JF (1989) Dendrites of hypothalamic magnocellular neurons release neurohypophysial peptides by exocytosis. Neuroscience 32:435-439.

Pumford KM, Russell JA, I eng G (1993) Effects of the selective kappa-opioid agonist U50,488 upon the electrical activity of supraoptic neurones in morphine-tolerant and morphine-naive rats. Exp Brain Res 94:237-246

Raby WN, Renaud LP (1989) Dorsomedial medulla stimulation activates rat supraoptic oxytocin and vasopressin neurones through different pathways. J Physiol (Lond) 417:279-294.

Russell JA, Gosden RG, Humphreys EM, Cutting R, Fitzsimons N, Johnston V, Liddle S, Scott S, Stirland JA (1989) Interruption of parturition in rats by morphine: a result of inhibition of oxytocin secretion. J Endocrinol 121:521-536.

Russell JA, Coombes JE, Leng G, Bicknell RJ (1993) Morphine tolerance and inhibition of oxytocin secretion by kappa-opioids acting on the rat neurohypophysis. J Physiol (Lond) 46:365-386.

Russell JA, Neumann I, Landgraf R, Douglas AJ (1994) Central oxytocin (OXT) and parturition in rats. Neuroendocrinology 60[Suppl 1]: 64-P3.5.

Shu S, Ju G, Fan L (1988) The glucose oxidase-DAB-nickel method in peroxidase histochemistry of the nervous system. Neurosci Lett 85:169-171.

Smith MS, Phalin CM, Hoffman GE (1994) Use of c-fos expression to map the neuroanatomical pathways activated by the suckling stimulus: brainstem and hypothalamic activation. Soc Neurosci Abstr 20: 862.

Summerlee AJS (1981) Extracellular recordings from oxytocin neurones during the expulsive phase of birth in unanaesthetized rats. J Physiol (Lond) 321:1-9.

Sumner BE, Douglas AJ, Russell JA (1992) Pregnancy alters the density of opioid binding sites in the supraoptic nucleus and posterior pituitary gland of rats. Neurosci Lett 137:216-220.

Ueta Y, Kannan H, Higuchi T, Negoro H, Yamashita H (1993) CCK-8 excites oxytocin-secreting neurons in the paraventricular nucleus in rats: possible involvement of noradrenergic pathway. Brain Res Bull 32:453-459.

Wardlaw SL, Frantz AG (1983) Brain beta-endorphin during pregnancy, parturition, and the postpartum period. Endocrinology 113:16641668.

Way SA, Leng G (1992) Relaxin increases the firing rate of supraoptic neurones and increases oxytocin secretion in the rat. $\mathbf{J}$ Endocrinol $132: 149-158$

Way SA, Douglas AJ, Dye S, Bicknell RJ, Leng G, Russell JA (1993) Endogenous opioid regulation of oxytocin release during parturition is reduced in ovariectomized rats. J Endocrinol 138:13-22.

Zhao BG, Chapman C, Bicknell RJ (1988) Functional kappa-opioid receptors on oxytocin and vasopressin nerve terminals isolated from the rat neurohypophysis. Brain Res 462:62-66. 